Bakir et al., Afr J Tradit Complement Altern Med., (2018) 15 (2): 80-87

https://doi.org/10.21010/ajtcam.v15i2.10

\title{
AMINO ACID COMPOSITION AND ANTIOXIDANT PROPERTIES OF FIVE EDIBLE MUSHROOM SPECIES FROM KASTAMONU, TURKEY
}

\author{
Temel kan Bakır $^{1 *}$, Mansor Boufars², Mertcan Karadeniz ${ }^{3}$, Sabri Ünal ${ }^{3}$ \\ ${ }^{1}$ Kastamonu University, Faculty of Science and Letters, Department of Chemistry, 37100, Kastamonu, \\ Turkey; ${ }^{2}$ Kastamonu University, Institute of Science, 37100, Kastamonu, Turkey; ${ }^{3}$ Kastamonu University, \\ Faculty of Forestry, Department of Forest Engineering, 37100, Kastamonu, Turkey.
}

*Corresponding Author's E-mail: temelkan@kastamonu.edu.tr

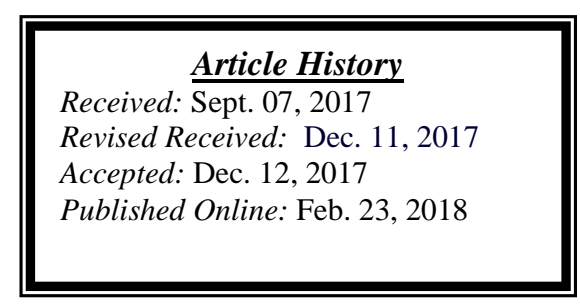

\begin{abstract}
Background: Hydnum repandum, Cantharellus cibarius, Ramaria fennica, Boletus edulis, and Craterellus cornucopioides are all wild edible mushroom species from the Kastamonu province. The aim of this study was to investigate antioxidant properties and amino acid contents of these mushrooms.

Materials and Methods: The mushrooms were analyzed for their free amino acid compositions using a high performance Amino Acid analyzer (Biochrom 30). Also, antioxidant activity and total phenolic concentrations of five different mushroom species were studied by using spectrophotometric methods.

Results: The mushrooms contained 17 amino acids (g/100 g): Glutamic acid (2.56-1.11), Alanine (1.49-0.54), Arginine (1.62-6.77), Aspartic acid (1.45-0.81), Leucine (1.08-0.64), Methionine (1.05-0.06), Valine (1.05-0.66), Lysine (1.01-0.57), Serine (0.68-0.38), Cysteine (0.88-0.11), Isoleucine (0.61-0.39), Glycine (0.82-0.35), Threonine $(0.82-0.44)$, Phenylalanine $(0.66-0.42)$, Proline $(0.60-0.47)$, Tyrosine $(0.58-0.38)$, and Histidine $(0.48-0.22)$. The total free amino acid (TAA) contents ranged from $169.2 \mathrm{mg} / \mathrm{g}$ in Boletus edulis to $89.1 \mathrm{mg} / \mathrm{g}$ in Hydnum repandum. These five different mushroom species contain eight essential amino acid species except tryptophan. The antioxidant activity of mushroom extracts was expressed as the percentage of DPPH radical inhibition and $\mathrm{IC}_{50}$ values $(\mathrm{mg} / \mathrm{mL})$. The percentage of inhibition ranged from $2.38 \%$ to $88.05 \%$ and $\mathrm{IC}_{50}$ values ranged from 0.03 to $13.98 \mathrm{mg} / \mathrm{mL}$. The total phenolic content ranged from 0.66 to $7.74 \mathrm{mg} / \mathrm{g}$ of dry mushroom extract, expressed as gallic acid equivalents.

Conclusion: Methanolic extract of Boletus edulis showed the highest phenolic content and strong antioxidant activity. As a result, the significant linear correlation between the values for the total phenolic content and antioxidant activity of mushroom extracts was corroborated in all of the investigated mushroom species, with the exception of Craterellus cornucopioides.
\end{abstract}

Key words: Edible mushrooms, Amino acids, Total phenolics, Antioxidant properties, Kastamonu

\section{Introduction}

Edible mushrooms are grown and consumed because of their delicious taste and a wide variety of aromatic flavors (Bailey and Day 1989, Breene 1990). They are used in traditional medicines because of their chemical properties. Mushrooms are rich in protein and carbohydrates and low in fat and calories. In addition, they contain high dietary fibers; edible vitamins (B1, B2, B12, C, D2 and E); and minerals (Kalač 2009). Phenolic acids are the major phenolic compounds found in mushrooms (Alispahić et al. 2015, Sun et al. 2017). Mushrooms are a good source of essential and non-essential amino acids (Chang and Miles 1989). The amino acid contents vary according to mushroom species (Ferreira et al. 2016) and are an indicator of the quality of the mushrooms and their nutritional value (Sudheep and Sridhar 2014, Teklit 2015). The taste of a mushroom is determined by the concentrations of aspartic and glutamic acids; sweet amino acids (alanine, glycine, and serine-threonine); bitter amino acids (arginine, histidine, isoleucine, leucine, methionine, phenylalanine, and valine); and tasteless amino acids (lysine and tyrosine) (Pomeranz 2012, Kalač 2016).

Mushrooms are useful candidates in the search for an effective antioxidant because of their naturally occurring composition (Jean-Philippe 2005). Certain mushrooms have been used as supplements to improve human health. Foods rich in antioxidants are now consumed more regularly because antioxidants or molecules with radical scavenging capacity are thought to exert a potential protective effect against free radical damage. These biomolecules prevent coronary and vascular diseases and tumor formation by inhibiting oxidative reactions. 
Although edible wild mushrooms are more expensive than cultivated mushrooms, their taste, nutrition, and pharmacological properties are becoming increasingly important in our diet. Cultivated and wild edible mushroom species have been widely investigated in the northern hemisphere; however, little is known about the antioxidant properties of wild edible mushrooms from Turkey (Gursoy et al. 2009), in particular, the amino acid and phenolic contents of the species Hydnum repandum (Hre), Cantharellus cibarius (Cci), Ramaria fennica (Rfe), Boletus edulis $(B e d)$, and Craterellus cornucopioides $(\mathrm{Cco})$ from the Kastamonu region. The aim of this study was to determine the antioxidant properties, phenolic compounds, and amino acid contents of these five mushroom species.

\section{Materials and Methods}

Hre, Cci, Rfe, Bed, and Cco were the five wild edible mushroom species studied herein. They are consumed regularly and are available at local markets in the Kastamonu province.

All analytical grade chemicals were purchased from Sigma-Aldrich Co. LLC. Deionized purity water was used at each stage. Absorbents were measured using a Shimadzu UVM-1240 UV-Visible spectrophotometer (Shimazu Corp., Kyoto, Japan), and Biochrom 30 was used for amino acid analysis.

\section{Sample collection and preparation}

Fresh mushrooms (Hre, Cci, Rfe, Bed, and $\mathrm{Cco}$ ) were collected from the towns of Inebolu, Taşköprü, and Devrekani of the Kastamonu province, Turkey (Table 1). The collected mushrooms were divided into $100 \mathrm{~g}$ samples. The samples were then dried at $30^{\circ} \mathrm{C}$ for $48 \mathrm{~h}$. The dried mushrooms were homogenously powdered for use in the analyses.

Table 1: Collection points and voucher numbers for each mushroom species

\begin{tabular}{lcl}
\hline \multicolumn{1}{c}{ Muhroom species } & Voucher Numbers* & \multicolumn{1}{c}{ Collection point } \\
\hline Boletus edulis & 370012 & Taşköprü - Kastamonu, Turkey \\
Cantharellus cibarius & 370013 & Inebolu- Kastamonu, Turkey \\
Craterellus cornucopioides & 370015 & Devrekani- Kastamonu, Turkey \\
Hydnum repandum & 370018 & Inebolu- Kastamonu, Turkey \\
Ramaria fennica & 370019 & Taşköprü- Kastamonu, Turkey \\
\hline
\end{tabular}

*Registration number for each mushroom species at Mushroom Research and Application Center of Kastamonu University.

\section{Mushroom identification}

The mushroom species were identified by Prof. Dr. Sabri ÜNAL at the Kastamonu University Mushroom Research and Application Center.

\section{Boletus edulis}

The average cap width of Bed is $24 \mathrm{~cm}$. The cap is reddish brown, flat, and slightly sticky to touch. The stipes is $17 \mathrm{~cm}$ long, club-shaped and yellowish white. The underside of the cap comprises thin tubes.

\section{Cantharellus cibarius}

$C c i$ is orange or yellow, meaty, and is funnel-shaped mushroom. Beneath the smooth cap, gill-like ridges run almost all the way down the stipe. The average cap width and stipe length are 6.8 and $5 \mathrm{~cm}$, respectively.

\section{Craterellus cornucopioides}

Cco is funnel shaped and gray, brown, or black. They often grow in small bunches, although sometimes they grow singly. It comprises a flower-like cap with an average width of $3.4 \mathrm{~cm}$. The stipe is hollow and very thin with an average height of $6.2 \mathrm{~cm}$.

\section{Hydnum repandum}

The tan-colored cap of Hre is generally irregular in shape with an average width of $11.6 \mathrm{~cm}$. The underside of cap is covered with small white spines that resemble those of a hedgehog. The stipe is $7.3 \mathrm{~cm}$ long and white.

\section{Ramaria fennica}

The average height and width of the fruiting body of $R f e$ are $10.8 \mathrm{~cm}$ and $7.2 \mathrm{~cm}$, respectively. The base is 4.8 $\mathrm{cm}$ wide, white, and well developed. The many branches are vertically oriented and elongated. The cap is smooth and olive-yellow.

\section{Analysis of free amino acid concentration}

Amino acid analysis was performed with a high performance amino acid analyzer (Biochrom 30). Hydrolysis was performed in a closed conical flask to determine all amino acids except tryptophan. Sample equivalent to $10 \mathrm{mg}$ of 
protein was weighed into the conical flask and mixed with $5 \mathrm{~mL}$ formic acid. The flask was placed in an ice bath for 16 $\mathrm{h}$ and sodium disulfite was added into the flask. $25 \mathrm{~mL}$ of $\mathrm{HCl} 6 \mathrm{~N}$ was then added to the oxidized mixture. The flask was oven dried at $110^{\circ} \mathrm{C}$ for $24 \mathrm{~h}$. The flask was then opened, and a Rotary evaporator was used to reduce the volume to $5-10 \mathrm{~mL}$ under vacuum at $60^{\circ} \mathrm{C}$. The $\mathrm{pH}$ was adjusted to 2.20 using sodium hydroxide solution. Sodium citrate buffer ( $\mathrm{pH}$ 2.20) was added to the hydrolyzed sample. Once all the soluble material was completely dissolved, the sample was ready for analysis (AOAC 2012).

\section{Analysis of antioxidant components \\ Preparation of mushroom extracts for antioxidant components}

For methanolic extractions, $5 \mathrm{~g}$ samples of each mushroom species were extracted by mixing with $30 \mathrm{~mL}$ of $80 \%$ methanol at $25^{\circ} \mathrm{C}$ for $3 \mathrm{~h}$ and filtration through Whatman filter paper (No.1). The residue was then extracted with two $20 \mathrm{~mL}$ portions of methanol. The combined ethanolic extracts were filtered through Whatman filter paper (No.1) after storing the extracts for $2 \mathrm{~h}$ at room temperature. The resulting homogenate was centrifuged at $5000 \mathrm{rpm}$ for 10 $\min \left(4^{\circ} \mathrm{C}\right)$. The derived supernatant was centrifuged at $7500 \mathrm{rpm}$ for $10 \mathrm{~min}$. The final supernatant $(100 \mathrm{mg} / \mathrm{mL}) \mathrm{was}$ used for 1,1-diphenyl-2-picrylhydrazyl (DPPH) measurements and stored at $4^{\circ} \mathrm{C}$ (Pedraza-Chaverri et al. 2004, Lee et al. 2004).

\section{Evaluation of antioxidant properties using the DPPH method}

The method proposed by Shimada et al. (1992) and Brand-Williams et al. (1995) was slightly modified, and free radical scavenging ability on DPPH was performed using the modified method. Different volumes (X: 0.05-0.20 $\mathrm{mL}$ ) of the extracts in methanol $(3-\mathrm{X} \mathrm{mL})$ were mixed with $3 \mathrm{~mL}$ of the methanolic solution containing DPPH (Sigma) radicals; the total volume of the reaction mixture was $6 \mathrm{~mL}$. This resulted in a final concentration of $\left(\right.$ stock $4.0 \times 10^{-4}$ M) DPPH. The mixture was shaken vigorously and left to stand for $30 \mathrm{~min}$ in the dark; the absorbance was then measured at $517 \mathrm{~nm}$ against a blank. The percentage radical scavenging activity was calculated from the following formula:

$\%$ scavenging $[\mathrm{DPPH}]=\left[\left(\mathrm{A}_{0}-\mathrm{A}_{1}\right) / \mathrm{A}_{0}\right] \times 100$,

Where $\mathrm{A}_{0}$ is the absorbance of the control solution (no antioxidant added) and $\mathrm{A}_{1}$ is the absorbance of the sample solution (when antioxidant was present) (Huang et al. 2005). The amount of antioxidant required to reduce the DPPH concentration by $50 \%$ is a commonly used parameter to measure the antioxidant activity and is called $\mathrm{IC}_{50}$ $(\mathrm{mg} / \mathrm{mL})$ (Frankel and Meyer 2000). The $\mathrm{IC}_{50}$ value was determined from the graph slope " $\mathrm{y}=\mathrm{mx}+\mathrm{c}$ " formula obtained from the inhibition (\%) concentration graph for mushroom extracts (Mukherjee et al. 2011).

\section{Determination of total phenolic content}

The concentration of phenolics in the mushroom extracts was determined using a spectrophotometric method (Singleton et al. 1999). A methanolic solution was used at a concentration of $1 \mathrm{mg} / \mathrm{mL}$. The reaction solution was prepared by mixing $0.5 \mathrm{~mL}$ of methanolic solution of mushroom extracts, $2.5 \mathrm{~mL}$ of $10 \%$ Folin Ciocalteu's reactant, which was dissolved in water, and $2.5 \mathrm{~mL} 7.5 \% \mathrm{NaHCO}_{3}$. The blank was prepared by adding $0.5 \mathrm{~mL}$ methanol to $2.5 \mathrm{~mL} \mathrm{10 \%} \mathrm{Folin} \mathrm{Ciocalteu's} \mathrm{reactant} \mathrm{dissolved} \mathrm{in} \mathrm{water,} \mathrm{and} 2.5 \mathrm{~mL}$ of $7.5 \% \mathrm{NaHCO}_{3}$. The samples were then incubated at $45^{\circ} \mathrm{C}$ for $45 \mathrm{~min}$. The same procedure was repeated for the gallic acid solution. The absorbance was determined using a spectrophotometer at $\lambda \max =765 \mathrm{~nm}$. The phenolic content of the extracts was expressed in terms of gallic acid equivalent ( $\mathrm{mg}$ of $\mathrm{GA} / \mathrm{g}$ of extract) after the concentration of phenolics (ppm) was read from the calibration line.

\section{Statistical analysis}

For each mushroom species, three samples were used; the antioxidant content of each was calculated using descriptive statistical analysis with Microcal Origin Pro 8.5.1 (Origin Lab. Corp., Northampton, MA, USA). Statistically significant effects were investigated using SPSS software (SPSS Inc., Chicago, IL, USA) for Windows version 13.

\section{Results and Discussion \\ Free amino acid concentrations in the five mushroom species}

In this study, eight essential and nine non-essential amino acid species were identified in the five wild mushroom species. In all five of the mushroom species, glutamic acid was the predominant non-essential amino acid. It was the main compound in Bed followed by Ref, Cci, Cco, and Hre. These results clearly indicate that glutamic acid, which is the major compound in all species, contributes to the primary taste of the mushrooms (Yamaguchi et al. 1971, Dutta et al. 2013). Several reports have shown that glutamic acid, which is an anti-cancer agent, is the highest total free amino acid (TAA) in mushrooms (Sato et al. 1985). 
The free amino acid content ranged from $5.8 \pm 0.01$ to $25.6 \pm 0.05 \mathrm{mg} / \mathrm{g}$ in $\mathrm{Bed}$, from $0.6 \pm 0.00$ to $11.1 \pm 0.03$ $\mathrm{mg} / \mathrm{g}$ in Hre, from $1.1 \pm 0.00$ to $17.5 \pm 0.02 \mathrm{mg} / \mathrm{g}$ in $\mathrm{Cci}$, from $1.8 \pm 0.00$ to $19.4 \pm 0.04 \mathrm{mg} / \mathrm{g}$ in Ref, and from $1.1 \pm$ 0.00 to $13.7 \pm 0.04 \mathrm{mg} / \mathrm{g}$ in Cco (Table 2 and Figure 1 ).

Table 2. Free amino acid content in Bed, Hre, Cci, Ref, and Cco

\begin{tabular}{lccccc}
\hline & \multicolumn{5}{c}{ Content (mg/g dry weight) } \\
\cline { 2 - 5 } Amino acid & $\begin{array}{c}\text { Hydnum } \\
\text { repandum }\end{array}$ & $\begin{array}{c}\text { Cantharellus } \\
\text { cibarius }\end{array}$ & $\begin{array}{c}\text { Ramaria } \\
\text { fennica }\end{array}$ & Boletus edulis & $\begin{array}{c}\text { Craterellus } \\
\text { cornucopioides }\end{array}$ \\
\hline Aspartic acid (Asp) & $8.1 \pm 0.03$ & $10.9 \pm 0.02$ & $11.5 \pm 0.04$ & $14.5 \pm 0.04$ & $9.4 \pm 0.03$ \\
Threonine (Thr) & $4.4 \pm 0.01$ & $5.9 \pm 0.01$ & $7.0 \pm 0.03$ & $8.2 \pm 0.03$ & $4.6 \pm 0.01$ \\
Serine (Ser) & $4.5 \pm 0.01$ & $5.9 \pm 0.01$ & $6.4 \pm 0.03$ & $6.8 \pm 0.03$ & $3.6 \pm 0.01$ \\
Glutamic acid (Glu) & $11.1 \pm 0.03$ & $17.5 \pm 0.02$ & $19.4 \pm 0.04$ & $25.6 \pm 0.05$ & $13.7 \pm 0.04$ \\
Glycine (Gly) & $3.5 \pm 0.01$ & $4.5 \pm 0.01$ & $5.8 \pm 0.01$ & $8.2 \pm 0.03$ & $4.5 \pm 0.01$ \\
Alanine (Ala) & $7.2 \pm 0.03$ & $7.4 \pm 0.03$ & $9.4 \pm 0.03$ & $15.1 \pm 0.03$ & $6.3 \pm 0.02$ \\
Valine (Val) & $7.7 \pm 0.03$ & $7.9 \pm 0.03$ & $8.8 \pm 0.03$ & $10.5 \pm 0.04$ & $6.6 \pm 0.03$ \\
Isoleucine (Iso) & $3.9 \pm 0.01$ & $4.8 \pm 0.01$ & $5.2 \pm 0.01$ & $6.1 \pm 0.03$ & $4.1 \pm 0.01$ \\
Leucine (Leu) & $7.1 \pm 0.03$ & $8.1 \pm 0.03$ & $8.8 \pm 0.03$ & $10.8 \pm 0.04$ & $6.4 \pm 0.03$ \\
Tyrosine (Tyr) & $4.7 \pm 0.01$ & $4.0 \pm 0.01$ & $4.3 \pm 0.01$ & $5.8 \pm 0.01$ & $3.8 \pm 0.01$ \\
Phenylalanine (Phe) & $5.0 \pm 0.02$ & $5.2 \pm 0.02$ & $6.1 \pm 0.03$ & $6.6 \pm 0.02$ & $4.6 \pm 0.02$ \\
Histidine (His) & $2.2 \pm 0.01$ & $3.0 \pm 0.01$ & $2.6 \pm 0.01$ & $4.8 \pm 0.01$ & $2.2 \pm 0.00$ \\
Lysine (Lys) & $6.0 \pm 0.02$ & $7.7 \pm 0.03$ & $6.5 \pm 0.03$ & $10.1 \pm 0.03$ & $5.7 \pm 0.02$ \\
Arginine (Arg) & $6.2 \pm 0.02$ & $14.9 \pm 0.04$ & $7.6 \pm 0.03$ & $10.9 \pm 0.04$ & $5.4 \pm 0.02$ \\
Prolin (Pro) & $5.3 \pm 0.01$ & $4.7 \pm 0.01$ & $6.0 \pm 0.03$ & $5.9 \pm 0.01$ & $5.1 \pm 0.01$ \\
Cysteine (Cys) & $1.6 \pm 0.01$ & $1.1 \pm 0.00$ & $2.7 \pm 0.01$ & $8.8 \pm 0.03$ & $4.5 \pm 0.01$ \\
Methionine (Met) & $0.6 \pm 0.00$ & $1.3 \pm 0.00$ & $1.8 \pm 0.00$ & $10.5 \pm 0.04$ & $1.1 \pm 0.00$ \\
\hline Each valy
\end{tabular}

Each value is expressed as mean \pm SD $(n=3)$. Means with different letters within a row are significantly different $(p<$ $0.05)$.

Several factors can affect the composition of mushrooms, including time of harvest, species, environmental factors, and method analysis (Manzi et al. 2001). Sun et al. (2017) reported that the total amino acid composition of 13 popular wild edible mushroom species from the Yunnan Province ranged from 14.62 to $131.06 \mathrm{mg} / \mathrm{g}$. The synergistic effect of glutamic and aspartic acid are thought to contribute to the umami taste of mushrooms (Baars et al. 2014). We found the maximum concentration of aspartic acid in Bed $(14.5 \pm 0.04 \mathrm{mg} / \mathrm{g})$ and the minimum aspartic acid concentration in Hre $(8.1 \pm 0.03 \mathrm{mg} / \mathrm{g})$.

Aspartic acid had the second largest concentration in four of the studied species (except $\mathrm{Cci}$ ), and the methionine concentration was low in $\mathrm{Hre}, \mathrm{Cco}$, and Cci, as reported by Ribeiro (2008).

Alanine was the most abundant compound in Bed. The concentration of serine was the highest in Bed, and lowest in Cco compared to all the other mushroom species. $C c i$ had the highest concentration of arginine, and the maximum concentration of cysteine was recorded in Bed, proline in Ref, and tyrosine in Bed. 


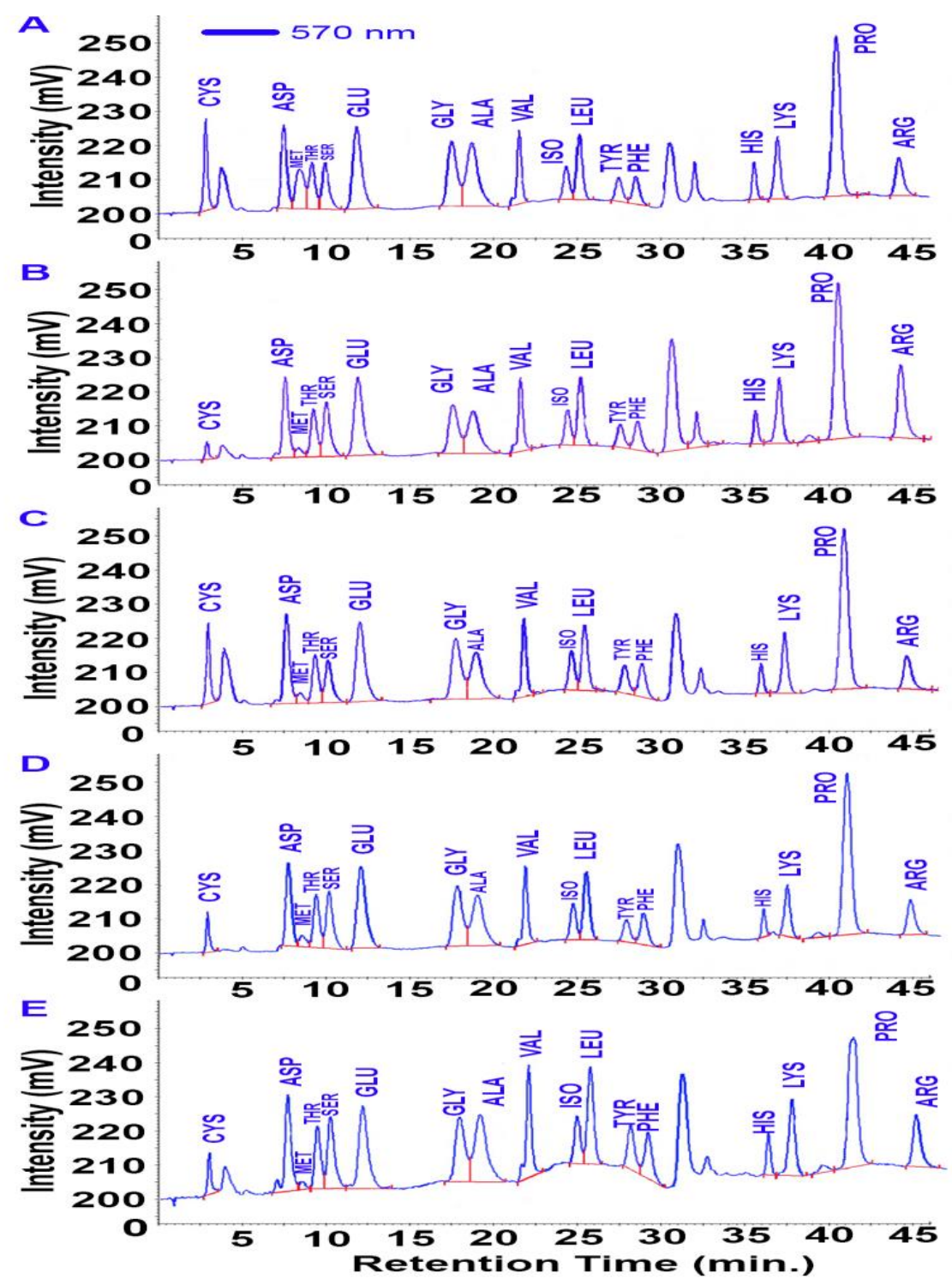

Figure 1. Typical chromatograms of free amino acids determined by high performance Amino Acid Analyzer Biochrom 30. (A) Boletus edulis, (B) Cantharellus cibarius, (C) Craterellus cornucopioides, (D) Ramaria fennica, and (E) Hydnum repandum. Cys (Cysteine), Asp (Aspartic acid), Met (Methionine), Thr (Threonine), Ser (Serine), Glu (Glutamic acid), Gly (Glycine), Ala (Alanine), Val (Valine), Iso (Isoleucine), Leu (Leucine), Tyr (Tyrosine), Phe (Phenylalanine), His (Histidine), Lys (Lysine), Pro (Proline), and Arg (Arginine).

Bed is the most abundant mushroom species in terms of essential amino acids. Histidine content was the lowest compared to the other amino acids. The highest concentrations of glutamic acid, methionine and valine were found in Bed. The lowest concentrations of valine and lysine were found in $C c o$; the lowest concentration of isoleucine $(3.9 \pm 0.01 \mathrm{mg} / \mathrm{g})$, glycine $(3.5 \pm 0.01 \mathrm{mg} / \mathrm{g})$, and threonine $(4.4 \pm 0.01 \mathrm{mg} / \mathrm{g})$ were found in Hre. Phenylalanine concentration was the highest in Bed and lowest in Cco. These results agree with those reported by Petrovska (2002), and the Boletus species are similar to those reported by Sun et al. (2017). In contrast, Ribeiro et al. (2008) and Tsai et al. (2008) reported low amino acid levels in Bed. Our findings for the amino acid distribution in Cci are similar to those reported by Danell and Eaker (1992), whereas Mdachi et al. (2004), Agrahar-Murugkar and Subbulakshmi (2005) and Ribeiro et al. (2008) found different values. Our findings for Cco are in agreement with those reported by Liu et al. (2012); however, although Beluhan and Ranogajec (2011) reported similar results for threonine and lysine, their findings for the other amino acids were different.

The amino acid composition in Rfe was similar in comparison to other Ramaria species, e.g., León-Guzmán et al. (1997) reported similar results in Ramaria flava, and Agrahar-Murugkar and Subbulakshmi (2005) also found low levels of amino acids in Ramaria brevispora. The lowest amino acid content in the mushroom samples was $89.1 \mathrm{mg} / \mathrm{g}$ in Hre, which was in agreement with the results presented by Kalač (2016).

The correlation between each mushroom species was significant at $\mathrm{p}<0.01$ and (r) values ranged from 0.728 to 0.962 for the 17 amino acids. When the correlation coefficients (r) were examined for the 17 amino acid species statistically, it was found that the lowest correlation existed between arginine (Arg) and proline (Pro). Arginine exhibited lower correlation values than the other amino acids. In contrast, the highest correlation coefficient was found to be 0.998 for ( $\mathrm{p}<0.01, \mathrm{n}=5$ ) significance between aspartic acid (Asp) and glutamic acid (Glu). 
The antioxidant properties and total phenolics assayed here are summarized in Table 3, and the results were explained as $\mathrm{IC}_{50}$ values (mg dry weight of various extracts per $\mathrm{mL}$ ) for comparison.

Table 3. Inhibition (\%) and $\mathrm{IC}_{50}$ values calculated using the DPPH method and total phenolic values measured using Folin Ciocalteu method for mushroom species

\begin{tabular}{|c|c|c|c|c|}
\hline & $\begin{array}{c}\text { Concentration } \\
(\mathrm{mg} / \mathrm{mL})^{*}\end{array}$ & $\begin{array}{c}\text { Inhibition } \\
(\%)\end{array}$ & $\begin{array}{c}\mathrm{IC}_{50} \\
(\mathrm{mg} / \mathrm{mL})\end{array}$ & $\begin{array}{c}\text { Total phenolics } \\
(\mathrm{mg} / \mathrm{L})\end{array}$ \\
\hline \multirow[t]{4}{*}{ *Boletus edulis } & 0.83 & 50.40 & 0.03 & 7742.2 \\
\hline & 1.67 & 86.53 & & \\
\hline & 2.50 & 87.91 & & \\
\hline & 3.33 & 88.05 & & \\
\hline \multirow[t]{4}{*}{ *Hydnum repandum } & 0.83 & 12.80 & 13.98 & 1320.9 \\
\hline & 1.67 & 13.95 & & \\
\hline & 2.50 & 14.71 & & \\
\hline & 3.33 & 20.61 & & \\
\hline \multirow[t]{4}{*}{ *Cantharellus cibarius } & 0.83 & 10.09 & 12.98 & 2178.8 \\
\hline & 1.67 & 12.38 & & \\
\hline & 2.50 & 15.85 & & \\
\hline & 3.33 & 18.09 & & \\
\hline \multirow[t]{4}{*}{ **Ramaria fennica } & 0.83 & 17.42 & 2.87 & 6431.6 \\
\hline & 1.67 & 39.17 & & \\
\hline & 2.50 & 40.36 & & \\
\hline & 3.33 & 57.45 & & \\
\hline \multirow[t]{4}{*}{ Craterellus cornucopioides } & 0.83 & 2.38 & 8.50 & 657.4 \\
\hline & 1.67 & 8.09 & & \\
\hline & 2.50 & 12.52 & & \\
\hline & 3.33 & 18.09 & & \\
\hline
\end{tabular}

Mushroom extract concentrations (c*): 0.83, 1.67, 2.50, $3.33 \mathrm{mg} / \mathrm{mL}$

The $95 \%$ confidence interval of the difference test for the concentration-inhibition pairs are significant at the $*_{p}<$ 0.01 and $* * \mathrm{p}<0.05$ level.

Percent inhibitions for each mushroom species increased in direct proportion with increasing mushroom concentration $(0.83-3.33 \mathrm{mg} / \mathrm{mL})$. Bed showed the highest antioxidant activity and Cco showed the lowest antioxidant activity when the concentrations were considered separately. DPPH radical scavenging capacities for mushroom species were determined by $\mathrm{IC}_{50}$ value. In scavenging ability on DPPH radicals, the effectiveness was in descending order: $($ Bed $)>($ Rfe $)>($ Cco $)>(C c i)>($ Hre $)$.

Total phenols were found in the range of 7.74-0.66 $\mathrm{mg}$ gallic acid equivalents/g for methanolic extracts as a major naturally occurring antioxidant component. The contents of total phenols were found in descending order of $(\mathrm{Bed})>(\mathrm{Rfe})>(\mathrm{Cci})>(\mathrm{Hre})>(\mathrm{Cco})$. The order of total phenolic contents exhibited similar results with $\mathrm{IC}_{50}$ values, with the exception of $C$ co.

A relative correlation between concentration and the percent of inhibition for each mushroom species was obtained. $C c o$ and $C c i$, which were measured by the DPPH method, showed a good significance $(\mathrm{p}<0.01, \mathrm{n}=4)$. The values ofr were 0.999 and 0.996 between concentration and the percent of inhibition, respectively. Likewise, Rfe showed good significance ( $\mathrm{p}<0.05, \mathrm{r}=0.955)$. Bed and Hre, which were also measured by the DPPH method, the values of $\mathrm{r}$ were 0.797 and 0.895 , respectively.

The $95 \%$ confidence interval of the difference test for the concentration-inhibition pairs was at a level of significance $\mathrm{p}<0.01$ for Bed, Hre, Cci, and $\mathrm{p}<0.05$ for $R f e$. The standard deviation value (SD) for concentrationinhibition comparisons was 1.075 .

Total phenolics are directly correlated with the change in antioxidant properties. Therefore, statistically correlation coefficients were found $(\mathrm{r}=-0.887)$ at the significant level $(\mathrm{p}<0.05)$ between total phenolic contents values and $\mathrm{IC}_{50}$ values for all mushrooms. Accordingly, the negative correlation found confirmed the inverse relation between $\mathrm{IC}_{50}$ and total phenolic concentration.

Ahmad and Mukhtar (1999) proposed good antioxidant properties of phenols because of their scavenging abilities on free radicals and chelating abilities on metal ions. Tsai et al. (2007) and Dubost et al. (2007) found a good correlation between total antioxidant components and polyphenols.

\section{Conclusion}

This study was conducted to assess the nutritional value of mushroom species that are widely consumed and form a commercial source of income in the Kastamonu region.

The results of the analysis show the essential and non-essential amino acid compositions of the mushrooms. In particular, non-essential amino acids such as glutamic acid, which also play a role in the formation of the essential 
amino acids, were found extensively in the studied mushroom species. Among these five mushroom species, Bed and $R f e$ had the highest antioxidant activity and amino acid contents. In addition, antioxidant activity and total phenolic substance concentrations for these mushroom species followed a linear correlation, with the exception of $C$ co. As a result, it was found that the total phenolic contents had a significant effect on the antioxidant activity, but the antioxidant activity was also determined by the different compositions. Antioxidant activity may also be affected by the amino acid content, which is responsible for typical mushroom tastes and natural values of these five mushroom species.

Conflict of interest: The authors have no conflict of interest in terms of the publication of this work.

Acknowledgments: I would like to thank Kastamonu University Center Research Laboratory and Mushroom Application Center.

\section{References}

1. Agrahar-Murugkar, D. and, Subbulakshmi, G. (2005). Nutritional value of edible wild mushrooms collected from the Khasi hills of Meghalaya. Food Chemistry 89(4): 599-603.

2. Ahmad, N. and, Mukhtar, H. (1999). Green tea polyphenols and cancer: Biologic mechanisms and practical implications. Nutrition Review 57: 78-83.

3. Alispahić, A., Šapčanin, A., Salihović, M., Ramić, E., Dedić, A. and, Pazalja, M. (2015). Phenolic content and antioxidant activity of mushroom extracts from Bosnian market. Bulletin of the Chemists and Technologist of Bosnia and Herzegovina 44: 5-8.

4. AOAC International (2012). Official Methods of Analysis of AOAC International. 19th edition. AOAC International, Gaithersburg, Maryland, USA

5. Baars, J.J.P., Stijger, I., Kersten, M., and, Sonnenberg, A.S.M. (2014). Differences in taste in button mushroom strains (Agaricus bisporus) (No. 2015-3). Wageningen UR Plant Breeding.

6. Bailey, C.J. and, Day, C. (1989). Traditional plant medicines as treatments for diabetes. Diabetes Care 12(8): 553-564.

7. Beluhan, S. and, Ranogajec, A. (2011). Chemical composition and non-volatile components of Croatian wild edible mushrooms. Food Chemistry 124(3): 1076-1082.

8. Brand-Williams, W., Cuvelier, M. and, Berset, C. (1995). Use of a free radical method to evaluate antioxidant activity. Lebensmittel-Wissenschaft \& Technologie 28: 25-30.

9. Breene, W.M. (1990). Nutritional and medicinal value of specialty mushrooms. Journal of Food Protection 53(10): 883-894.

10. Chang, S. and, Miles, P. (1989). The nutritional attributes and medicinal value of edible mushrooms. Edible Mushrooms and Their Cultivation 27-40.

11. Danell, E. and, Eaker, D. (1992). Amino acid and total protein content of the edible mushroom Cantharellus cibarius (Fries). Journal of the Science of Food and Agriculture 60(3): 333-337.

12. Dubost, N.J., Ou, B. and, Beelman, R.B. (2007). Quantification of polyphenols and ergothioneine in cultivated mushrooms and correlation to total antioxidant capacity. Food Chemistry 105: 727-735.

13. Dutta, S., Ray, S. and, Nagarajan, K. (2013). Glutamic acid as anticancer agent: An overview. Saudi Pharmaceutical Journal 21(4): 337-343.

14. Ferreira, I.C., Morales, P. and, Barros, L. (2016). Wild Plants, Mushrooms and Nuts: Functional Food Properties and Applications. John Wiley and Sons.

15. Frankel, E.N. and, Meyer, A.S. (2000). The problems of using onedimensional methods to evaluate multifunctional food and biological antioxidants. Journal of the Science of Food and Agriculture 80: 19251941.

16. Gursoy, N., Sarikurkcu, C., Cengiz, M., and Solak, M.H. (2009). Antioxidant activities, metal contents, total phenolics and flavonoids of seven Morchella species. Food and Chemical Toxicology 47(9): 2381-2388.

17. Huang, D., Ou, B. and, Prior, L. (2005). The Chemistry behind Antioxidant Capacity Assays. Journal Agricultural and Food Chemistry 53(6): 1841-1856.

18. Jean-Philippe, S.R. (2005). Antioxidant Properties of Some Edible Fungi in The Genus Pleurotus. Master's Thesis, University of Tennessee

19. Kalač, P. (2009). Chemical composition and nutritional value of European species of wild growing mushrooms: A review. Food Chemistry 113(1): 9-16.

20. Kalač, P. (2016). Edible mushrooms: chemical composition and nutritional value. Academic Press.

21. Lee, D.H., Kima, J.H., Park, J.S., Choi, Y.J. and, Lee, J.S. (2004). Isolation and characterization of a novel angiotensin I-converting enzyme inhibitory peptide derived from the edible mushroom Tricholoma giganteum. Peptides 25: 621-627.

22. León-Guzmán, M.F., Silva, I. and, López, M.G. (1997). Proximate chemical composition, free amino acid contents, and free fatty acid contents of some wild edible mushrooms from Querétaro, México. Journal of Agricultural and Food Chemistry 45(11): 4329-4332. 
23. Liu, Y.T., Sun, J., Luo, Z.Y., Rao, S.Q., Su, Y.J., Xu, R.R. and, Yang, Y.J. (2012). Chemical composition of five wild edible mushrooms collected from Southwest China and their antihyperglycemic and antioxidant activity. Food and Chemical Toxicology 50(5): 1238-1244.

24. Manzi, P., Aguzzi, A. and Pizzoferrato, L. (2001). Nutritional value of mushrooms widely consumed in Italy. Food Chemistry 73(3): 321-325.

25. Mdachi, S.J., Nkunya, M.H., Nyigo, V.A. and, Urasa, I.T. (2004). Amino acid composition of some Tanzanian wild mushrooms. Food Chemistry 86(2): 179-182.

26. Mukherjee, S., Pawar, N., Kulkarni, O., Nagarkar, B., Thopte, S., Bhujbal, A. and Pawar, P. (2011). Evaluation of free-radical quenching properties of standard Ayurvedic formulation Vayasthapana Rasayana. BMC Complementary and Alternative Medicine 11: 38-43.

27. Pedraza-Chaverri, J., Gil-Ortiz, M., Albarran, G., Barbachano-Esparza, L., Menjivar, M. and, MedinaCampos, O. (2004). Garlic's ability to prevent in vitro $\mathrm{Cu}^{2+}$-induced lipoprotein oxidation in human serum is preserved in heated garlic: effect unrelated to $\mathrm{Cu}^{2+}$-chelation. Nutrition Journal 3: 10 .

28. Petrovska, B.B. (2002). An evaluation of the protein quality of some macedonian edible Boletaceae mushrooms. Midazolam-sirupus, formulation and pharmacodynamic efficacy, 21.

29. Pomeranz, Y. (2012). Functional properties of food components: Academic Press.

30. Ribeiro, B., Andrade, P.B., Silva, B.M., Baptista, P., Seabra, R.M. and, Valentão, P.C. (2008). Comparative study on free amino acid composition of wild edible mushroom species. Journal of Agricultural and Food Chemistr, 56(22): 10973-10979.

31. Sato, E., Aoyagi, Y. and, Sugahara, T. (1985). Contents of free amino acids in mushrooms. Nippon Shokuhin Kogyo Gakkaishi 32(7): 509-521.

32. Shimada, K., Fujikawa, K., Yahara, K. and, Nakamura, T. (1992). Antioxidative properties of xanthan on the autoxidation of soybean oil in cyclodextrin emulsion. Journal of Agricultural and Food Chemistry 40: 945948.

33. Singleton, V.L., Orthofer, R. and, Lamuela-Raventos, R.M. (1999). Analysis of total phenols and other oxidation substrates and antioxidants by means of Folin-Ciocalteu reagent. Methods in Enzymology 299: 152178.

34. Sudheep, N.M. and, Sridhar, K.R. (2014). Nutritional composition of two wild mushrooms consumed by the tribals of the Western Ghats of India. Mycology 5(2): 64-72.

35. Sun, L., Liu, Q., Bao, C. and, Fan, J. (2017). Comparison of Free Total Amino Acid Compositions and Their Functional Classifications in 13 Wild Edible Mushrooms. Molecules 22(3): 350.

36. Teklit, G. (2015). Chemical Composition and Nutritional Value of the Most Widely Used Mushrooms Cultivated in Mekelle Tigray Ethiopia. Journal of Nutrition and Food Sciences 5(5): 1.

37. Tsai, S.Y., Tsai, H.L. and, Mau, J.L. (2007). Antioxidant properties of Agaricus blazei, Agrocybe cylindracea and Boletus edulis. LWT-Food Science and Technology 40: 1392-1402.

38. Tsai, S.Y., Tsai, H.L. and, Mau, J.L. (2008). Non-volatile taste components of Agaricus blazei, Agrocybe cylindracea and Boletus edulis. Food Chemistry 107(3): 977-983.

39. Yamaguchi, S., Yoshikawa, T., Ikeda, S. and Ninomiya, T. (1971). Measurement of the relative taste intensity of some 1- $\alpha$-amino acids and 5'-nucleotides. Journal of Food Science 36(6): 846-849. 